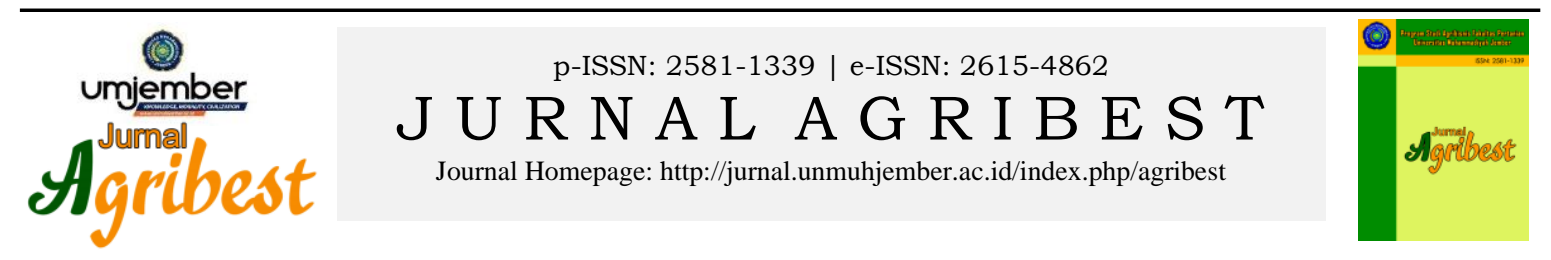

\title{
Analisis Kepuasan Peternak Sapi Perah Terhadap Program Asuransi Usaha Ternak Sapi (Auts) Di Kecamatan Getasan
}

\section{Analysis Of Dairy Farmers Satisfaciton To Cattle Livestock Business Insurance (Auts) Program In Getasan District}

Fiska Irsina Nadhila, Wulan Sumekar, Agus Subhan prasetyo

Universitas Diponegoro

Email: Fiskanadhila@gmail.com,wulan_Sumekar@yahoo.co.id, setyo.subhan@live.undip.ac.id

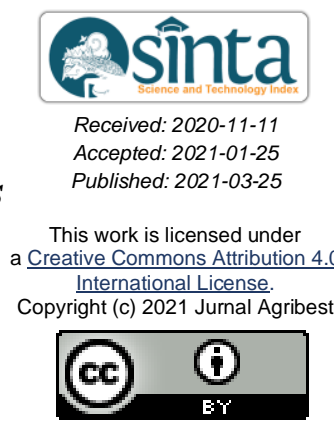

Corresponding author: Fiska Irsina Nadhila, Universitas Diponegoro, Fiskanadhila@gmail.com

\begin{abstract}
ABSTRAK
Usaha ternak sapi dalam pelaksanannya tidak terlepas dari risiko yang menyebabkan kerugian. Namun, kerugian tersebut dapat diminimalisir dengan mengikuti asuransi. Penelitian ini telah dilaksanakan pada bulan Agustus 2020 di Kecamatan Getasan, Kabupaten Semarang. Lokasi penelitian dipilih dengan sengaja dengan pertimbangan bahwa lokasi penelitian sudah menjalankan program AUTS dan merupakan sentra sapi perah di Kabupaten Semarang. Tujuan dari penelitian ini adalah menganalisis atribut yang menjadi prioritas untuk memperbaiki kinerja program AUTS dan menganalisis tingkat kepuasan peternak sapi perah terhadap program AUTS. Metode analisis data yang digunakan yaitu Importance Performance Analysis (IPA) dan Consumer Satisfaction Index (CSI). Hasil analisis IPA menunjukkan bahwa atribut yang masih perlu untuk ditingkatkan adalah ketepatan waktu pembayaran klaim dan tanggapan mengenai nominal harga pertanggungan. Hasil perhitungan CSI menunjukkan tingkat kepuasan peternak secara keseluruhan adalah sebesar 96,1\% yang berarti bahwa peternak merasa puas dengan program AUTS.
\end{abstract}

Kata kunci:Asuransi, CSI, kepuasan peternak, IPA, Sapi perah

\section{ABSTRACT}

The cattle bussiness in implementation can't be seperated from risk that causes losses but it can be reduced by joining insurance. This research was conducted in August 2020 in Getasan Regency, Semarang. Research location was selected purposively with consideration that Getasan Regency has implemented AUTS program and become the center of dairy farms. This research aimed to analyze attributes priority that can improve AUTS performance and analyze the dairy farmer's satisfaction level to AUTS program. Data analysis method using Importance Performance Analysis (IPA) and the Consumer Satisfaction Index (CSI). Based on IPA analysis, attributes that still need to be improved were timeliness of claim payments and the response related to the nominal price of insurance. Based on CSI calculations, the dairy farmer's satisfaction level reach 96,1\% that means dairy farmers are satisfied with the performance of AUTS program.

Keywords:CSI, dairy cattle, dairy farmers satisfaction, Insurance, IPA

\section{PENDAHULUAN}

Sapi perah merupakan hewan ternak yang populasinya banyak tersebar di Indonesia. Populasi sapi perah di Indonesia pada tahun 2018 mencapai 550.141 ekor dengan populasi sapi perah terbanyak berada di Provinsi Jawa Barat sebanyak 265.002 ekor dan peringkat kedua berada di Provinsi Jawa Tengah yaitu sebanyak 134.721 ekor (BPS, 2019). Banyaknya populasi sapi perah di Indonesia dikarenakan mayoritas penduduk Indonesia merupakan petani yang umumnya berada di pedesaan dan masih mengkombinasikan usahatani tanaman dengan ternak khususnya sapi perah.

Kebutuhan susu segar dalam negeri (SSDN) mencapai 3,8 juta ton/tahun. Produksi susu sapi nasional sebesar 798.000 ton hanya mampu memenuhi kebutuhan SSDN sebesar 21\% dari peternak dalam negri sehingga sebanyak $79 \%$ harus diimpor oleh pemerintah dalam upaya memenuhi 
kebutuhan susu di Indonesia (Kementan, 2018). Upaya yang dapat dilakukan dalam meningkatkan produksi SSDN yaitu dengan mengembangkan usaha ternak sapi perah rakyat sehingga peternak dapat meningkatkan produksi susu dan susu impor dapat berkurang.

Melalui pengembangan usaha ternak sapi perah, peternak dapat meningkatkan produksi susu dan susu impor dapat berkutang. Namun, pada pelaksanaannya, usaha ternak sapi perah memiliki risiko yang tinggi diantaranya adalah kehilangan hingga kematian ternak akibat wabah penyakit, kecelakaan, dan melahirkan. Risiko tersebut dapat menyebabkan peternak mengalami kerugian finansial. Risiko didefinisikan sebagai peluang munculnya sesuatu yang tidak diinginkan yang dapat mengakibatkan kerugian atau hasil yang tidak diinginkan (Basyaib, 2007). Risiko dalam usaha ternak dapat diminimalisir apabila peternak mengansurasikan ternak miliknya.

Kementerian Pertanian (Kementan) pada tahun 2016 mengeluarkan program yang bernama Asuransi Usaha Ternak Sapi (AUTS). Kementan dalam melaksanakan Program AUTS bekerjasama dengan PT. Jasa Asuransi Indonesia (Jasindo). Mengacu pada Keputusan Menteri Pertanian Nomor 18/KPTS/PK.240/B/12/2017 dalam Pedoman Asuransi Usaha Ternak Sapi/Kerbau (AUTS/K) asuransi ternak merupakan perjanjian antara perusahaan asuransi sebagai penanggung dengan peternak sebagai tertanggung dimana dengan menerima premi asuransi, perusahaan asuransi akan memberikan penggantian kerugian kepada peternak karena sapi/kerbau mati akibat penyakit, kecelakaan dan beranak, dan/atau kehilangan sesuai ketentuan dan persyaratan polis asuransi. Program AUTS bertujuan untuk memberikan perlindungan kepada peternak dalam bentuk ganti rugi akibat kematian atau kehilangan ternak sapi atau kerbau melalui skema pertanggungan asuransi, sehingga usaha ternaknya dapat terus berlanjut.

Program AUTS sudah dijalankan di berbagai daerah di Indonesia salah satunya di Kabupaten Semarang. Program AUTS di Kabupaten Semarang sudah dijalankan di lima kecamatan salah satunya di Kecamatan Getasan. Kecamatan Getasan merupakan kecamatan yang memiliki populasi sapi perah terbanyak di Kabupaten Semarang. Populasi sapi perah di Kecamatan Getasan pada tahun 2018 mencapai 16.403 ekor dengan jumlah produksi susu 18.009.225 liter (BPS, 2019).

Program AUTS sangat menguntungkan bagi peternak, karena pada atribut subsidi premi pemerintah memberikan sebesar $80 \%$ dari harga premi yang seharusnya dibayar dan sisanya sebesar $20 \%$ merupakan swadaya peternak. Atribut merupakan karakteristik produk atau jasa yang digunakan untuk mengembangkan produk atau jasa tersebut (Kotler \& Armstrong, 2012). Meskipun pemerintah sudah memberikan subsidi tetapi kesadaran peternak terhadap pentingnya asuransi masih rendah. Kesan yang melekat di pikiran peternak mengenai asuransi adalah prosesnya yang rumit. Peternak cenderung akan mengikuti suatu program yang ditawarkan apabila sudah melihat bukti dari manfaat yang akan mereka terima. Peternak mulai tertarik mengikuti asuransi ketika melihat peternak lain yang sudah mendapatkan klaim asuransinya.

Peternak yang sudah mendapatkan klaim asuransi sudah merasakan manfaat dari pelaksanaan program AUTS. Peternak menjadi tidak rugi ketika ternaknya mengalami kematian. Penelitian ini memilik tujuan yaitu untuk menganalisis atribut yang menjadi prioritas untuk memperbaiki kinerja program AUTS dan menganalisis tingkat kepuasan peternak sapi perah terhadap program AUTS.

\section{METODE PENELITIAN}

Penelitian ini dilaksanakan pada bulan Agustus 2020 di Kecamatan Getasan, Kabupaten Semarang, Provinsi Jawa Tengah. Lokasi penelitian dipilih dengan pertimbangan bahwa lokasi penelitian sudah menjalankan program AUTS dengan populasi sapi perah terbanyak dan merupakan sentra susu sapi di Kabupaten Semarang. Responden berjumlah 56 peternak diambil secara purposive sampling dengan kriteria merupakan peternak sapi perah di Kecamatan Getasan yang sudah pernah mengikuti program AUTS dan sudah pernah melakukan klaim asuransi. Pengumpulan data dilakukan dengan wawancara dengan kuesioner dan observasi.

Penilaian tingkat kepentingan dan kepuasan disusun berdasarkan Pedoman Bantuan Premi Asuransi UsahaTernak Sapi/Kerbau Direktorat Pembiayaan Pertanian tahun 2018. Atribut yang diteliti antara lain adalah tanggapan peternak mengenai kriteria ternak untuk didaftarkan, kemudahan persyaratan pendaftaran, kemudahan prosedur pendaftaran, tanggapan peternak mengenai nominal premi asuransi, tanggapan peternak mengenai nominal subsidi premi asuransi, 
kemudahan persyaratan pengajuan klaim, kemudahan prosedur pengajuan klaim, ketepatan waktu mendapatkan persetujuan klaim, ketepatan waktu pembayaran klaim, tanggapan mengenai nominal harga pertanggungan, pengetahuan petugas dalam mengatasi permasalahan yang dihadapi peternak, kecepatan dalam menanggapi keluhan peternak, dan kemudahan peternak untuk menghubungi petugas. Atribut tersebut diukur menggunakan skala likert. Skala likert adalah pengukuran yang digunakan untuk memudahkan responden memilih skala yang lebih mendekati kenyataan yang sebenarnya atas pelayanan yang sudah diterima (Supranto, 2006). Skor penilaian skala likert adalah sebagai berikut:

Tabel 1.Skor Penilaian Tingkat Kepentingan dan Tingkat Kinerja

\begin{tabular}{ccc} 
Skor & Tingkat Kepentingan & Tingkat Kinerja \\
\hline 1 & Tidak penting & Tidak Puas \\
2 & Cukup penting & Cukup Puas \\
3 & Penting & Puas \\
\hline
\end{tabular}

(Sumber: Prihati, 2011)

Data dianalisis menggunakan Importance Performance Analysis (IPA) dan Costumer Satisfied Index (CSI). IPA dilakukan untuk menjawab tujuan pertama dari penelitian ini.Tahapan dalam menganalisis pelayanan AUTS berdasarkan tingkat kepentingan dan tingkat kinerja menggunakan Importance Performance Analysis (IPA) menurut (Supranto, 2006) adalah sebagai berikut:

a. Menghitung tingkat kesesuaian dengan rumus:

Tki $=\frac{\mathrm{x}_{\mathrm{i}}}{\mathrm{y}_{\mathrm{i}}} \times 100 \%$

Keterangan:

Tki : Tingkat kesesuaian

$\mathrm{x}_{\mathrm{i}} \quad$ : Skor penilaian kinerja

$\mathrm{y}_{\tilde{\mathrm{i}}} \quad$ : Skor penilaian kepentingan

a. Menghitung rata-rata penilaian setiap atribut dengan rumus:

$\overline{\mathrm{x}}_{\mathrm{i}}=\frac{\sum \mathrm{x}_{\mathrm{i}}}{\mathrm{n}} \overline{\mathrm{y}}_{\mathrm{i}}=\frac{\sum \mathrm{y}_{\mathrm{i}}}{\mathrm{n}}$

Keterangan:

$\overline{\mathrm{x}}_{\mathrm{i}} \quad$ : Rata-rata skor tingkat kinerja atribut

$\overline{\mathrm{y}}_{\mathrm{i}} \quad$ : Rata-rata skor tingkat kepentingan terhadap atribut

n : Jumlah responden

b. Menghitung nilai rata-rata seluruh atribut tingkat kepentingan $(\mathrm{Y})$ dan kinerja $(\mathrm{X})$ yang menjadi batas dalam diagram kartesius dengan rumus:

$\overline{\bar{x}}_{\mathrm{i}}=\frac{\sum \overline{\mathrm{x}}_{\mathrm{i}}}{\mathrm{k}} \overline{\mathrm{y}}_{\mathrm{i}}=\frac{\sum \overline{\mathrm{y}}_{\mathrm{i}}}{\mathrm{k}}$

Keterangan:

$\overline{\overline{\mathrm{x}}}_{\mathrm{i}} \quad$ : Rata-rata skor tingkat kinerja seluruh atribut

$\overline{\bar{y}}_{\hat{\mathrm{i}}} \quad$ : Rata-rata skor tingkat kepentingan atribut yang mempengaruhi kepuasan.

$\mathrm{k} \quad$ : Banyak atribut yang dapat mempengaruhi kepuasan

c. Melakukan pemetaan ke dalam diagram kartesius 


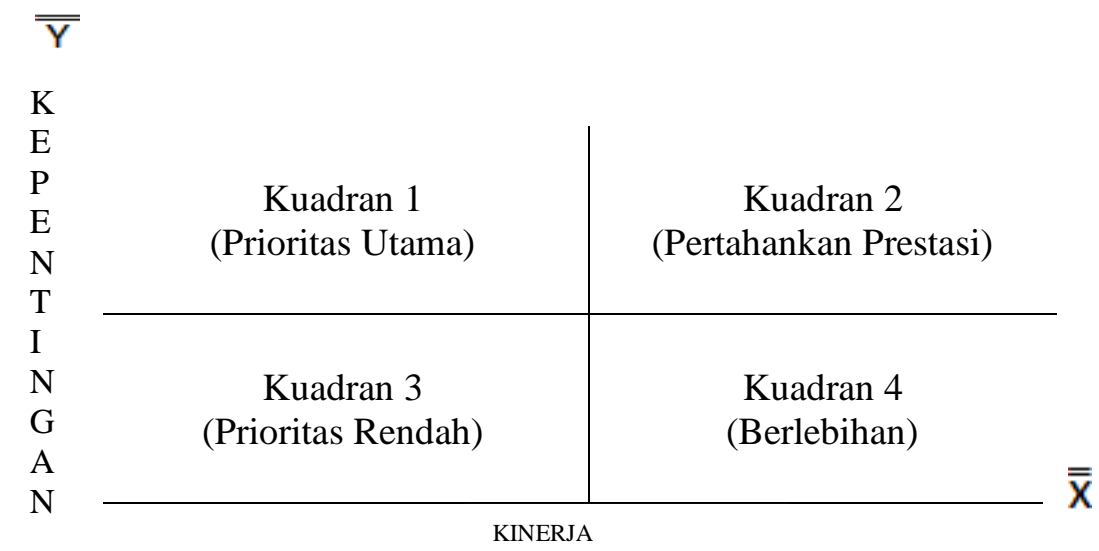

Gambar 1. Diagram Kartesius

CSI dilakukan untuk menjawab tujuan kedua dari penelitian ini Tahapan dalam menganalisis kepuasan peternak sapi perah dengan menggunakan Costumer Satisfied Index (CSI) menurut (Tedjaningsih, Suyudi, \& Nuryaman, 2018) adalah sebagai berikut:

a. Menentukan Mean Importance Score (MIS) dan Mean Satisfaction Score (MSS) dengan rumus:

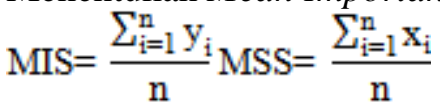

Keterangan:

$y_{i}$ : Nilai kepentingan atribut ke-i

$\mathrm{x}_{\mathrm{i}}$ : Nilai kinerja atribut ke-i

$\mathrm{n}$ : Jumlah responden

b. Menghitung Wight Factor (WF) dengan rumus:

$$
\mathrm{WF}=\frac{M S^{\prime}}{\sum_{\mathrm{i}=1}^{p} \mathrm{MIS}_{\mathrm{i}}} \times 100 \%
$$

Keterangan:

$\mathrm{P}$ : Jumlah atribut kepentingan

i : Atribut ke-i

c. Menghitungt Weight Score (WS) dengan rumus:

$\mathrm{WSi}=\mathrm{WFi} \times \mathrm{MSS}$

Keterangan:

i : Atribut ke-i

d. Menentukan Satisfaction Index dengan rumus:

$\mathrm{CSI}=\frac{\sum_{\mathrm{i}=1}^{\mathrm{n}} \mathrm{WSi}}{\mathrm{HS}} \times 100 \%$

Keterangan:

HS: Skala maksimum yang digunakan

Indeks kepuasan menggunakan rentang skala untuk menunjukkan tingkat kepuasan dengan rumus sebagai berikut:

$\mathrm{RS}=\frac{\mathrm{m}-\mathrm{n}}{\mathrm{b}}$

Keterangan:

m : skor tertinggi

n : skor terendah

b : jumlah kategori yang dibuat 
Penelitian ini menggunakan rentang skala sebagai berikut:

$$
\mathrm{RS}=\frac{100 \%-0 \%}{3}=33,33 \%
$$

Tabel 2.Nilai Indeks Kepuasan

\begin{tabular}{ccc}
\hline No & Nilai Index & Keterangan \\
\hline 3 & $66,7 \%-100 \%$ & Puas \\
4 & $33,4 \%-66,6 \%$ & Cukup Puas \\
5 & $0 \%-33,3 \%$ & Tidak Puas \\
\hline
\end{tabular}

\section{Karakteristik Responden}

\section{HASIL DAN PEMBAHASAN}

Karakteristik responden pada penelitian ini dibahas berdasarkan usia, tingkat pendidikan, pekerjaan dan alasan mengikuti AUTS. Mayoritas peternak sapi perah berada pada rentang usia produktif 25 - 55 tahun $(73,22 \%)$. Usia produktif peternak dengan rentang usia $20-65$ tahun berada pada usia yang mampu melakukan pekerjaan produktif secara efisien hingga dapat meghasilkan pendapatan (Tatipikalawan, 2017).

Tingkat pendidikan peternak masih tergolong rendah dengan mayoritas berada pada tingkat $\mathrm{SD} /$ sederajat $(35,71 \%)$. Hal tersebut akan berdampak kepada pelaksanaan usaha ternak. Pendidikan dapat menambah pengetahuan serta keterampilan peternak sehingga akan meningkatkan produktivitas yang pada akhirnya akan menentukan keberhasilan usaha ternak (Fauziyah, Nurmalina, \& Burhanuddin, 2015). Tingkat pendidikan peternak juga berpengaruh dalam membantu peternak untuk menerapkan prinsip-prinsip teknologi yang digunakan dalam peternakan (Dalmiyatun, Roessali, Sumekar, \& Mardiningsih, 2015).

Mayoritas peternak memiliki pekerjaan utama di sektor pertanian dan peternakan $(89,28 \%)$. Hal ini berhubungan dengan kondisi daerah penelitian yang berada di ketinggian $415-1.450$ mdpl yang dimanfaatkan oleh masyarakat untuk budidaya tanaman pangan, bunga dan perkembangbiakan sapi perah. Sapi perah perlu dipelihara di daerah sejuk dengan ketinggian mulai dari $600-1.300 \mathrm{mdpl}$ dan suhu $15^{\circ} \mathrm{C}-22^{\circ} \mathrm{C}$ (Nurdin, 2011). Hal ini dilakukan agar sapi perah dapat beproduksi secara optimal. Alasan utama peternak dalam mengikuti AUTS adalah untuk mengurangi risiko $(62,16 \%)$. Hal ini menunjukkan bahwa sebagian besar peternak sudah mengerti akan risiko yang dihadapi dalam usaha ternak sapi sehingga mereka memilih untuk mengasuransikan ternaknya dibandingkan merugi dan menyesal di kemudian hari.

\section{Kesesuaian Antara Kepentingan Peternak dengan Kinerja AUTS,}

Tingkat kesesuaian antara kepentingan dengan kinerja adalah persentase perbandingan antara skor penilian kinerja dengan skor penilaian kepentingan. Skor penilaian kinerja diperoleh dari penilaian peternak terhadap pelaksanaan dan pelayanan program AUTS. Sedangkan skor penilaian kepentingan diperoleh dari penilaian peternak mengenai harapan atau keinginan terhadap program AUTS. Presentase tingkat kesesuaian berdasarkan atribut kepentingan dan kinerja AUTS terlampir pada tabel 3 .

Berdasarkan tabel 5 terdapat sebelas atribut yang memiliki nilai kesesuaian diatas nilai rata-rata $97,5 \%$. Sebelas atribut tersebut adalah tanggapan peternak mengenai kriteria ternak untuk didaftarkan (98,8\%), kemudahan persyaratan pendaftaran AUTS (98,8\%), kemudahan prosedur pendaftaran AUTS (101,2\%), tanggapan peternak mengenai nominal subsidi premi asuransi $(99,4 \%)$, kemudahan persyaratan pengajuan klaim $(99,4 \%)$, kemudahan prosedur pengajuan klaim (97,6\%), ketepatan waktu mendapatkan persetujuan klaim (97,5\%), tingkat pengetahuan petugas dalam mengatasi permasalahan yang dihadapi peternak (100,6\%), kecepatan petugas dalam menanggapi keluhan peternak $(98,2 \%)$, dan kemudahan peternak untuk menghubungi petugas (97,6\%). Atribut tersebut dinilai sudah sesuai dengan harapan peternak. (Yulianti \& Wahdah, 2018) mengatakan bahwa atribut yang memiliki tingkat kesesuaian mendekati $100 \%$ dan berada diatas rata-rata tingkat kesesuaian maka atribut tersebut sudah memenuhi harapan peternak. 
Tabel 3. Persentase Tingkat Kesesuaian Berdasarkan Atribut Kepentingan dan Kinerja

\begin{tabular}{|c|c|c|}
\hline No & Atribut & $\begin{array}{c}\text { Tingkat } \\
\text { Kesesuaian }\end{array}$ \\
\hline & & $\ldots . . \% \ldots$ \\
\hline 1 & Tanggapan peternak mengenai kriteria ternak untuk didaftarkan & 98,8 \\
\hline 2 & Kemudahan persyaratan pendaftaran AUTS & 98,8 \\
\hline 3 & Kemudahan prosedur pendaftaran AUTS & 101,2 \\
\hline 4 & Tanggapan peternak mengenai nominal premi asuransi & 102,5 \\
\hline 5 & Tanggapan peternak mengenai nominal subsidi premi asuransi & 99,4 \\
\hline 6 & Kemudahan persyaratan pengajuan klaim & 99,4 \\
\hline 7 & Kemudahan prosedur pengajuan klaim & 97,6 \\
\hline 8 & Ketepatan waktu mendapatkan persetujuan klaim & 97,5 \\
\hline 9 & Ketepatan waktu pembayaran klaim & 84,5 \\
\hline 10 & Tanggapan mengenai nominal harga pertanggungan & 91,7 \\
\hline 11 & $\begin{array}{l}\text { Tingkat pengetahuan petugas dalam mengatasi permasalahan yang } \\
\text { dihadapi peternak }\end{array}$ & 100,6 \\
\hline 12 & Kecepatan petugas dalam menanggapi keluhan peternak & 98,2 \\
\hline 13 & Kemudahan peternak untuk menghubungi petugas & 97,6 \\
\hline
\end{tabular}

(Sumber: Data Primer diolah, 2020)

Atribut yang memiliki tingkat kesesuaian dibawah rata-rata 97,5\% yaitu ketepatan waktu pembayaran klaim $(84,5 \%)$ dan tanggapan mengenai nominal harga pertanggungan $(91,7 \%)$. Kedua atribut tersebut dinilai masih belum sesuai dengan harapan peternak. Nilai tingkat kesesuaian yang berada dibawah rata-rata, maka atribut tersebut masih belum memenuhi tingkat harapan peternak terhadap pelayanan (Yulianti \& Wahdah, 2018).

\section{Posisi Kepentingan dan Kinerja pada Kuadran IPA}

Posisi kepentingan dan kinerja diperoleh dengan menggunakan metode Importance performance Analysis (IPA). IPA adalah analisis untuk mengukur pelayanan AUTS berdasarkan tingkat kepentingan dan tingkat kinerja serta untuk mengetahui atribut yang menjadi prioritas untuk memperbaiki kinerja perusahaan dalam meningkatkan kepuasan (Putri, Eddy, \& Dalmiyatun, 2018). Analisis IPA akan digunakan untuk menentukan sumbu $X$ yaitu kinerja dan sumbu $Y$ yaitu kepentingan pada diagram Kartesius. Sumbu $\mathrm{X}$ dan $\mathrm{Y}$ ini akan membagi diagram ke dalam 4 kuadran sehingga dapat mengetahui atribut yang menjadi prioritas utama yang perlu ditingkatkan kembali pelaksanaan serta pelayanannya. Diagram kartesius termapir pada gambar 2 di bawah ini.

Berdasarkan gambar 2 dapat diketahui bahwa seluruh atribut tersebar pada Kuadran I, II, dan IV. Terdapat dua atribut yang termasuk kedalam kuadran I atau yang menjadi priorits utama adala ketepatan waktu pembayaran klaim (9) dan tanggapan mengenai nominal harga pertanggungan (10). Kuadran I dalam diagram kartesius merupakan wilayah yang membuat atribut dengan tingkat kepentingan tinggi tetapi memiliki tingkat kinerja rendah sehingga atribut tersebut harus ditingkatkan kinerjanya dan menjadi prioritas dari lembaga (Supranto, 2006).

Atribut yang termasuk kedalam kuadran II atau yang perlu dipertahankan antara lain tanggapan peternak mengenai nominal subsidi premi asuransi (5), kemudahan persyaratan pengajuan klaim (6), kemudahan prosedur pengajuan klaim (7), ketepatan waktu mendapatkan persetujuan klaim (8), kecepatan petugas dalam menanggapi keluhan peternak (12), dan Kemudahan peternak untuk menghubungi petugas (13). Menurut (Supranto, 2006) menyatakan bahwa kuadran II menunjukkan atribut-atribut yang dianggap sangat penting oleh peternak dan telah dilaksanakan oleh lembaga terkait. Aspek-apsek yang masuk pada kuadran ini harus tetap dipertahankan dan harus terus dikelola dengan baik. 


\section{Diagram Kartesius}

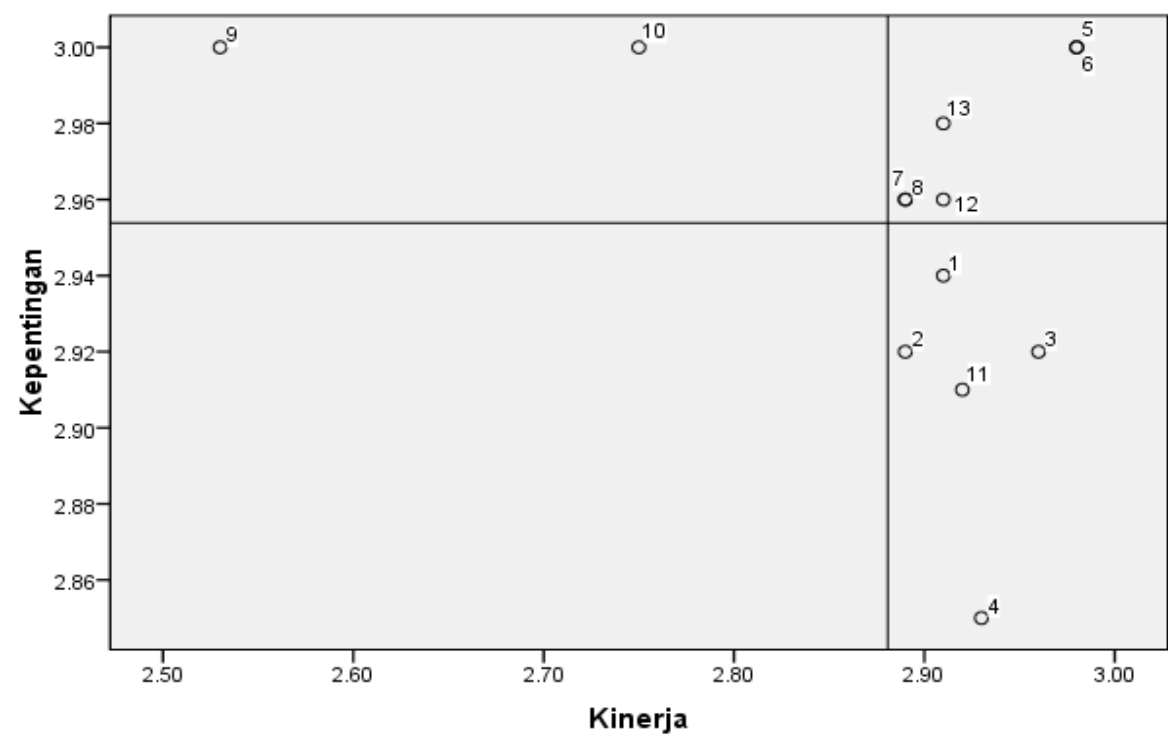

Gambar 2. Diagram Kartesius Perhitungan IPA

(Sumber: Data Primer diolah, 2020)

Tidak terdapat atribut di kuadran III. Hal ini berarti bahwa tidak ada atribut yang menjadi prioritas rendah karena peternak menilai tidak ada atribut yang tidak penting namun memiliki kinerja yang baik. Atribut yang termasuk kedalam kuadran IV atau yang berlebihan terdapat lima atribut yaitu tanggapan peternak mengenai kriteria ternak untuk didaftarkan (1), kemudahan persyaratan pendaftaran AUTS (2), kemudahan prosedur pendaftaran AUTS (3), tanggapan peternak mengenai nominal premi asuransi (4), tingkat pengetahuan petugas dalam mengatasi permasalahan yang dihadapi peternak (11). Atribut yang berada di kuadran IV menunjukkan atribut-atribut yang dianggap kurang penting oleh peternak, tetapi dalam pelaksanaannya telah dilakukan dengan baik (Supranto, 2006).

\section{Analisis Costumer Satisfied Index (CSI)}

Costumer Satisfied Index (CSI) adalah analisis yang digunakan untuk mengetahui tingkat kepuasan konsumen atau pengguna jasa secara keseluruhan melalui tingkat kinerja dan tingkat kepentingan dari atribut yang ada (Irawan, 2002). CSI dihitung dengan memperhitungkan skor kepentingan dan kinerja dari seluruh atribut yang digunakan. Hasil perhitungan CSI terlampir pada tabel 4.

Tabel 4 menunjukkan bahwa nilai CSI yang diperoleh adalah sebesar 96,1\%. Nilai CSI tersebut berada pada indeks kepuasan antara 66,7\% - 100\% yang menunjukkan bahwa secara keseluruhan peternak sapi perah merasa puas dengan program AUTS. Indeks kepuasan dihitung menggunakan rumus rentang skala yaitu selisih skor tertinggi dengan skor terendah dibagi dengan kategori yang diinginkan, maka didapatkan nilai indeks yaitu 0\%-33,3\% (tidak puas), 33,4\%-66,6\% (cukup puas) dan 66,7\%-100\% (puas) (Tedjaningsih et al., 2018).

Kepuasan yang dirasakan peternak apabila dihubungkan dengan diagram kartesius pada perhitungan IPA, terlihat bahwa jumlah atribut pada kuadran II dan kuadran IV sebanyak 11 atribut. Jumlah atribut tersebut lebih banyak dibanding jumlah atribut pada kuadran I dan III yaitu dua atribut. Kuadran II dan IV menunjukkan tingkat kepuasan peternak terhadap AUTS berada di atas rata-rata nilai kinerja, sedangkan pada kuadran I dan III menunjukkan tingkat kepuasan peternak terhadap program AUTS berada dibawah rata-rata nilai kinerja.

Walaupun tingkat kepuasan peternak secara keseluruhan dinyatakan puas, tetapi jika dihubungkan dengan tingkat kesesuaian dan perhitungan IPA masih terdapat atribut yang perlu 
ditingkatkan kembali. Atribut yang memiliki tingkat kesesuaian dibawah rata-rata tingkat kesesuaian yaitu ketepatan waktu pembayaran klaim dan tanggapan mengenai nominal harga pertanggungan. Peternak merasa atribut ini masih belum memenuhi harapan mereka. Pembayaran klaim yang terlambat membuat peternak tidak bisa membeli bibit sapi baru dengan segera sehingga usaha ternak mereka jadi sedikit terhambat.

Tabel 4. Hasil Perhitungan CSI

\begin{tabular}{ccccc}
\hline Atribut & $\begin{array}{c}\text { Mean Importance Score } \\
\text { (MIS) }\end{array}$ & $\begin{array}{c}\text { Mean Satisfaction Score } \\
\text { (MSS) }\end{array}$ & $\begin{array}{c}\text { Wight Factor } \\
\text { (WF) }\end{array}$ & $\begin{array}{c}\text { Weight } \\
\text { Score } \\
\text { (WS) }\end{array}$ \\
\hline X1 & 2,94 & 2,91 & 0,077 & 0,22 \\
X2 & 2,92 & 2,89 & 0,076 & 0,22 \\
X3 & 2,92 & 2,96 & 0,076 & 0,22 \\
X4 & 2,85 & 2,93 & 0,074 & 0,22 \\
X5 & 3,00 & 2,98 & 0,078 & 0,23 \\
X6 & 3,00 & 2,98 & 0,078 & 0,23 \\
X7 & 2,96 & 2,89 & 0,077 & 0,22 \\
X8 & 2,96 & 2,89 & 0,077 & 0,22 \\
X9 & 3,00 & 2,53 & 0,078 & 0,20 \\
X10 & 3,00 & 2,75 & 0,078 & 0,21 \\
X11 & 2,91 & 2,92 & 0,076 & 0,22 \\
X12 & 2,96 & 2,91 & 0,077 & 0,22 \\
X13 & 2,98 & 2,91 & 0,077 & 0,22 \\
\hline TOTAL & 38,45 & 37,48 & 1 & 2,88 \\
& & & CSI & 96,1 \\
\hline
\end{tabular}

(Sumber: Data Primer diolah, 2020)

Harga pertanggungan yang diberikan juga tidak sesuai ekspektasi peternak. Peternak mengharapkan nilai pertanggungan yang sebanding dengan harga sapi mereka. Oleh karena itu, untuk dapat meningkatkan kepuasan peternak dalam pelaksanan program AUTS ini, pihak asuransi perlu untuk meningkatkan kinerja dari kedua atribut tersebut agar peternak merasa lebih puas dan indeks kepuasan dapat mencapai nilai $100 \%$. Konsumen merasa puas jika harapan atas produk dan jasanya dapat terpenuhi dan merasa sangat puas jika harapan konsumen atas produk dan jasa terlampaui (D. Irawan \& Japarianto, 2013).

\section{KESIMPULAN}

Berdasarkan hasil pembahasan maka dapat disimpulkan atribut yang menjadi prioritas utama adalah atribut yang termasuk kuadran I yaitu ketepatan waktu pembayaran klaim dan tanggapan mengenai nominal harga pertanggungan. Kedua atribut tersebut dinilai belum memenuhi harapan peternak sehingga dalam pelaksanannya masih perlu di tingkatkan kembali. Hasil perhitungan CSI menunjukkan bahwa tingkat kepuasan peternak secara keseluruhan adalah sebesar 96,1\% yang berarti bahwa peternak merasa puas dengan program AUTS.

\section{DAFTAR PUSTAKA}

Basyaib, F. 2007. Manajemen Risiko. Jakarta: Grasindo.

BPS. 2019. Kabupaten Semarang Dalam Angka 2019. Semarang: BPS Kabupaten Semarang.

Dalmiyatun, T., Roessali, W., Sumekar, W., \& Mardiningsih, D. 2015. Analisis Kebutuhan Untuk Peningkatan Usaha Peternakan Sapi Perah di Kecamatan Ungaran Timur Kabupaten Semarang. SEPA, 12(1), 95-100.

Fauziyah, D., Nurmalina, R., \& Burhanuddin. 2015. Pengaruh Karakteristik Peternak Melalui Kompetensi Terhadap Kinerja Usaha Ternak Sapi Potong di Kabupaten Bandung. Jurnal 
Agribisnis Indonesia, 3(2), 83-96.

Irawan, D., \& Japarianto, E. 2013. Analisis Pengaruh Kualitas Produk Terhadap Loyalitas Melalui Kepuasan Sebagai Variabel Intervening Pada Pelanggan Restoran Por kee Surabaya. Jurnal Manajemen Pemasaran, 1(2), 1-8.

Irawan, H. 2002. 10 Prinsip Kepuasan Pelanggan. Jakarta: PT Elex Media Komputindo.

Kementan. 2018. Outlook Susu. Jakarta: Kementerian Pertanian.

Kementan. 2018. Pedoman Bantuan Premi Asuransi Usaha Ternak Sapi/Kerbau Direktorat Pembiayaan Pertanian. Jakarta: Kementrian Pertanian.

Kotler, P., \& Armstrong, G. 2012. Principles of Marketing. England: Pearson Education Limited.

Nurdin. 2011. Mnajemen Sapi Perah. Tanggerang: Graha Ilmu.

Prihati, Y. 2011. Model Matematis Pembandingan Tingkat Kepentingan Dan Kinerja Yang Dirasakan Untuk Menentukan Tingkat Kepuasan Pelanggan. Ilmiah Informatika, 2(2), 1-14.

Putri, B. A. H., Eddy, B. T., \& Dalmiyatun, T. 2018. Jurnal Sosial Ekonomi Pertanian ISSN 25800566 EISSN 2621-9778. Agrisocionomics, 2(2), 85-93.

Supranto, J. 2006. Pengukuran Tingkat Kepuasan Pelanggan. Jakarta: Rineka Cipta.

Tatipikalawan, J. M. 2017. Socio-Economic Characteristics and Constraints of Production and Marketing of Lakor Goat Farmers in Lakor Island of Maluku Province. Jurnal Budidaya Pertanian, 13(2), 68-73.

Tedjaningsih, T., Suyudi, \& Nuryaman, H. 2018. Peran Kelembagaan Dalam Pengembangan Agribisnis Mendong. Jurnal Pemikiran Masyarakat Ilmiah Berwawasan Agribisnis, 4(2), 210-226.

Yulianti, F., \& Wahdah, R. 2018. Analisis Indeks Kepuasan Masyarakat (IKM) dan Kualitas Pelayanan Publik (Studi Pada PDAM Bandarmasih di Banjarmasin). Jurnal Ecoment Global, 3(2), 84-102. 
Jurnal Agribest Volume 5 Nomor 1 (2021) Hal: 9-17

DOI: https://doi.org/ 10.32528/agribest.v5i1.3770 